\title{
Trend Analysis of Annual and Seasonal Rainfall in Tawa command Area
}

\author{
Sourabh Nema, M.K Awasthi, R K Nema
}

Dept. of Soil and Water Engineering, College of Agricultural Engineering, JNKVV, Jabalpur, M.P. India

\begin{abstract}
The main objective of the study is to identify the trend in annual rainfall time series data as well as seasonal rainfall time series of four rainy months i.e. June, July, August and September during the period of 1971 to 2015. The annual \& sessional trend of rainfall was determinedby non-parametric Mann-Kendall test. Also a non-parametric Sen's Slope estimator was used for the determination of magnitude of trend. A functional relationship has been developed between variables using linear regression analysis in order to determine a linear trend of rainfall for the study area. The study concludes considering the result of all statistical test results, that the study area has shown variability in annual \& sessional rainfall pattern due to climatic variations. Also the sessional trend analysis of rainfall has suggested that there is a trendvariationof rainfall in the rainymonths.
\end{abstract}

Keywords - Trend analysis, Time Series, Mann-Kendall test, Sen's estimator, Regression analysis.

\section{INTRODUCTION}

The Indian agriculture is largely dependent on the monsoon rainfall, which accounts for 80 per cent of the total rainfall in the subcontinent. In recent times, the climate is witnessing alarming changes. According to a new studycarried out by Stanford Woods Institute for the Environment, average total seasonal rain shown a declinefor the duration periodof 1980-2011. It was observed that changes in the climate like increasing temperature, winds and moisture which are likely to be responsible for changes in wet and dry spells. The variations in climate and rainfall pattern is the highly concerning issue now a days in India. Efforts being made by several researchers to assess \& mitigate the risk resulting from change in climatic environment by suggesting various techniques in order to achieve sustainability. Rainfall is a vital factor which needs a considerable attention as Indian agriculture is severely affected due to any variation in rainfall pattern. Previous study suggested that the changes in Monsoon, particularly south west monsoon have a significant impact on the Indian region as it can severely impact on agricultural production, water resources management and overall economy of the country (Jain and Kumar (2012). The changes in climatic factors affects the crop development stages subsequently degrading the yield as well as quality. The ambient temperature and rainfall are the most influencing climatic parameters which can affect the progressive stages, development and crop yield. In general, most of the cases, the overall growth of crops and their yields are mostly reliant on the monsoon rain as the sowing of crop for rabi season is also getting the essential soil moisture, which has retained from the later parts of the monsoon. Hence varying rainfall pattern and their influence on agriculture crop production and water resources remains a major climatic issue in recent times. In order to reduce the dependency on climatic factors, especially on rainfall, the proper planning and management of our land \& water resources are quite essential. The importance of understanding rainfall trend is essential for agriculture future as the sense and awareness of trend and variability of rainfall can contribute help to supply supplemental water for crops during their critical growth stages. With the help of trend analysis, scientists has discovered some grave consequences of climate change. The purpose of a trend analysis is to determine whether the values of a series generally increase or decrease. Trend analysis is used to assess the impact of a particular trend and to evaluate the extent of that trend. Trend analysis determines whether the observed values of any variable increase or decrease on a certain period of time.

In a recent past, several researchers had done research to identify the metrological trends in order to check and overcome the extreme metrological events (Chhabra et al., 1997; Easterling et al., 2000; Francis and Gadgil, 2006; Griffiths et al., 2003; Guhathakurta and Rajeevan, 2006; Haylock, 2000, 2006; Jain and Kumar, 2012; Kunkel, 2003;many methods i.e. parametric and non-parametric, have been applied for determining the trends. MannKendall (MK) test (Mann, 1945; Kendall, 1975) is one of the commonly used non-parametric tests for determining a trend in hydrologic time series. The current study was accomplished using the trend of seasonal rainfall using Mann- Kendall, regression analysis and Sen's Slope statistics for the determination of the trend of rainfall. The Indian monsoon (June to September) rainfall is very crucial for the economic development, disaster management, hydrological planning for the country. (Guhathakurta and Rajeevan, 2006). 
II. METHODOLOGY

Study area: The study area selected for the present study is Tawa command area, lies in Hoshangabad District of Madhya Pradesh. The study area is bounded by Satpura ranges in south and by Narmada River in the north. The area slopes North West toward the Narmada River. The slope of the study area is generally steep at the foothills of Satpura but moderate to gentle towards Narmada River. The entire study is drained by Narmada River and its tributaries. Thus the area falls in the Narmada Basin. The River Narmada flows along the northern boundary of the district.

Trend analysis for hydro-meteorological variables such as rainfall, mean temperature, relative humidity, wind speed and streamflow has been of specific interest to hydrologists and researchers for several years. The previous studies suggested that the most widely used method is the nonparametric Mann-Kendall test. Trend study for rainfall of the study area covered mainly of three steps; first was to determine the trend whether increasing, decreasing or no trend by Mann-Kendall (non-parametric) test in the annual as well as seasonal rainfall data series, second part of the study is to estimate the magnitude of trend by using Sen's slopeestimator and third was to develop regression models for the observed rainfall data series.

\section{Mann-Kendall Test (Non- parametric)}

The use of the Mann-Kendall (MK) test (Mann 1945, Kendall 1975 , Gilbert 1987) is to statistically measure if there is a monotonic rising or downward trend of the variable of interest over time. An upward trend means that the variable consistently increases through time and vice versa, but the trend may or may not be linear. The MK test can be applied in place of a parametric linear regression analysis, if the gradient of the linear regression is other than zero. The regression analysis requires that the residuals from the fitted regression line to be normally distributed.

The MK statistics ( $\mathrm{S}$ ) is defined as,

$$
S=\sum_{i=1}^{N-1} \sum_{j=i+1}^{N} \operatorname{sgn}\left(x_{j}-x_{i}\right)
$$

where $\mathrm{N}$ is number of data points. Assuming $\left(x_{j}-x_{i}\right)=$ $\theta$, the value of $\operatorname{sgn}(\theta)$ is computed as follows;

$$
\operatorname{sgn}(\theta)=\left\{\begin{array}{cll}
1 & \text { if } & \theta>1 \\
0 & \text { if } & \theta=1 \\
-1 & \text { if } & \theta<1
\end{array}\right.
$$

This statistics represents that the number of positive differences minus the number of negative differences. If is a positive number, observations obtained later in time tend to be larger than observations made earlier. If is a negative number, then observations made later in time tend to be smaller than observations made earlier.
$\mathrm{E}[\mathrm{S}]=0$

$$
\operatorname{Var}(S)=\frac{N(N-1)(2 N+5)-\sum_{k=1}^{n} t_{k}\left(t_{k}-1\right)\left(2 t_{k}+5\right)}{18}
$$

Where $\mathrm{N}$ is the number of zero change values with respect to compared values, and $\mathrm{t}_{\mathrm{k}}$ is the number of data points in the $k^{\text {th }}$ matched group.

The number of observation grater then 10 observation, then variance of $\mathrm{S}$ has been calculated by above equation.

The Standard normal deviate (Z-statistics) is then computed as:

$$
Z=\left\{\begin{array}{ccc}
\frac{S-1}{\sqrt{\operatorname{Var}(S)}} & \text { if } & S>0 \\
0 & \text { if } & S=0 \\
\frac{S+1}{\sqrt{\operatorname{Var}(S)}} & \text { if } & S<0
\end{array}\right.
$$

A positive (negative) value of indicates that the data tend to increase (decrease) with time.

\section{Sen's Estimator}

The extent of trend in a hydrologic time series can be determined using non-parametric method known as Sen's estimator (Sen, 1968). This method assumes a linear trend in the time series. In this method, the slopes (Ti) of all data pairs are calculated first by

$\mathrm{Q}$ is a slope estimate.

$$
Q=\frac{Y_{i}^{\prime}-Y_{i}}{i^{\prime}-i}
$$

$\mathrm{Yi}$ ' are $\mathrm{Yi}$ the values at times i' and $i$, where $i$ ' is greater than $i$,

$\mathrm{N}^{\prime}$ is all data pairs for which $\mathrm{i}^{\prime}$ is greater than $\mathrm{i}$.

Sen's estimator of slope is the median of the N' values of $\mathrm{Q}$. The same procedure is followed whether there are one or multiple observations per time period. A positive value of $Q$ indicates an upward trend and a negative value indicates a downward trend in the time series.

\section{Regression Analysis}

Regression analysis is a statistical process for estimating the relationships among variables. It includes many techniques for modeling and analyzing several variables, when the focus is on the relationship between a dependent variable and one or more independent variables. This is parametric analysis which assumes normal distribution of time series data. The regression analysis is generally applied for testing a linear trend by developing inner relationship between time and the variable of interest. The precise use of this method needs the variables to be distributed normally and spatial and temporal independent. The regression analysis was performed on the observed rainfall time series data. In a specific station, Trend in rainfall can be studied by regression analysis with respect to time as the independent 
variable and annual and sessional rainfall as the dependent variable. A linear equation, $y=m x+c$, defined by $c$ (the intercept) and trend $\mathrm{m}$ (the slope), which represents the rate of increase or decrease of the variable, can be fitted by regression and $t$ is time in years.

\section{RESULTS AND DISCUSSION}

Trend analysis of annual rainfall data as well as seasonal rainfall data (June - September) has been analyzed by Mann-Kendall and Sen's Slope Estimator in this study for evaluating trend and magnitude for Hoshangabad District. The Regression analysis has also been used for developing linear relationship between observed rainfall data with respect to time. The results obtained using annual rainfall trend analysis are given in Table 1 . The mean rainfall of the study area over 44 years was found to be $1125.76 \mathrm{~mm}$. following are the results obtained from Mann kindle test.

Table.1: Annual rainfall Trend results for Mann-Kendall test, Sen's Slope estimator and Regression Analysis

\begin{tabular}{|l|r|}
\hline Statistical parameters & Calculated values \\
\hline Kendall's tau & -0.057 \\
\hline $\mathrm{S}$ & -54.000 \\
\hline Var(S) & 9771.333 \\
\hline p-value (Two-tailed) & 0.592 \\
\hline alpha & 0.05 \\
\hline
\end{tabular}

As per Table 1, the computed p-value using annual rainfall data is greater than the significance level alpha $=0.05$, one cannot reject the null hypothesis $\mathrm{H} 0$ which assumes that there are no trend exists so it means that annual rainfall observations obtained over time are independent, identically distributed and there is no significant trend in annual rainfall over long term.

Table.2: Seasonal rainfall Trend results for Mann-Kendall test, Sen's Slope estimator and Regression Analysis

\begin{tabular}{|c|c|c|c|c|}
\hline $\begin{array}{c}\text { Statistical } \\
\text { Parameters }\end{array}$ & June & July & Aug & Sep \\
\hline $\begin{array}{c}\text { Kendall's } \\
\text { tau }\end{array}$ & -0.004 & 0.224 & -0.147 & -0.060 \\
\hline
\end{tabular}

\begin{tabular}{|c|c|c|c|c|}
\hline$S$ & -4.000 & 211.000 & -57.00 & -57.000 \\
\hline Var(S) & 9771.333 & 9770.333 & 9767.66 & 9767.667 \\
\hline $\begin{array}{c}\text { p-value } \\
\text { (Two- } \\
\text { tailed })\end{array}$ & 0.976 & 0.034 & 0.571 & 0.571 \\
\hline alpha & 0.05 & 0.05 & 0.05 & 0.05 \\
\hline Sen's Slope & -0.01 & 0.557 & -2.784 & -0.557 \\
\hline $\begin{array}{c}\text { Regression } \\
\text { Analysis }\end{array}$ & June & July & Aug & Sept \\
\hline $\begin{array}{c}\text { Slope }(m) \\
\text { Intercept } \\
(c)\end{array}$ & 2.0577 & 0.0163 & 3.612 & -2.076 \\
\hline
\end{tabular}

It is evident from Fig-1 that the maximum rainfall occurs in study area in Month of June, July, August and September. It has been also observed that the seasonal rainfall received during month of June (average $139.5 \mathrm{~mm}$ ) was lowest than the other months which were considered for the study followed by September (average $156.18 \mathrm{~mm}$ ), then July (average 352.86) and maximum rainfall was received on August (416.72. This analysis revealed negative (decreasing) trend for June, August and September whereas Kendall'stau values indicated a positive trend for July month. The Sen' estimator which is to measure the magnitude of seasonal rainfall was found as -.01, 0.557, 2.784 and -0.557 for June, July, August and September respectively.

The Regression analysis was performed for the Annual rainfall time series data as well as the seasonal rainfall time series data for the month of June, July, August and September are showed in the Fig-1, Fig-2, Fig-3, Fig-4, Fig5 and Fig-6 respectively. The developed functional relationships for the variables is also showed in the figures. Table.2represent the regression analysis values of for all the four months (i.e. June, July, August, and September). The slope coefficient specifies the rate of change in the rainfall characteristic. The sign of the slope describes the direction of the trend of the rainfall, if sign is positive then it has increasing trend and if sign is negative then it has decreasing trend. 


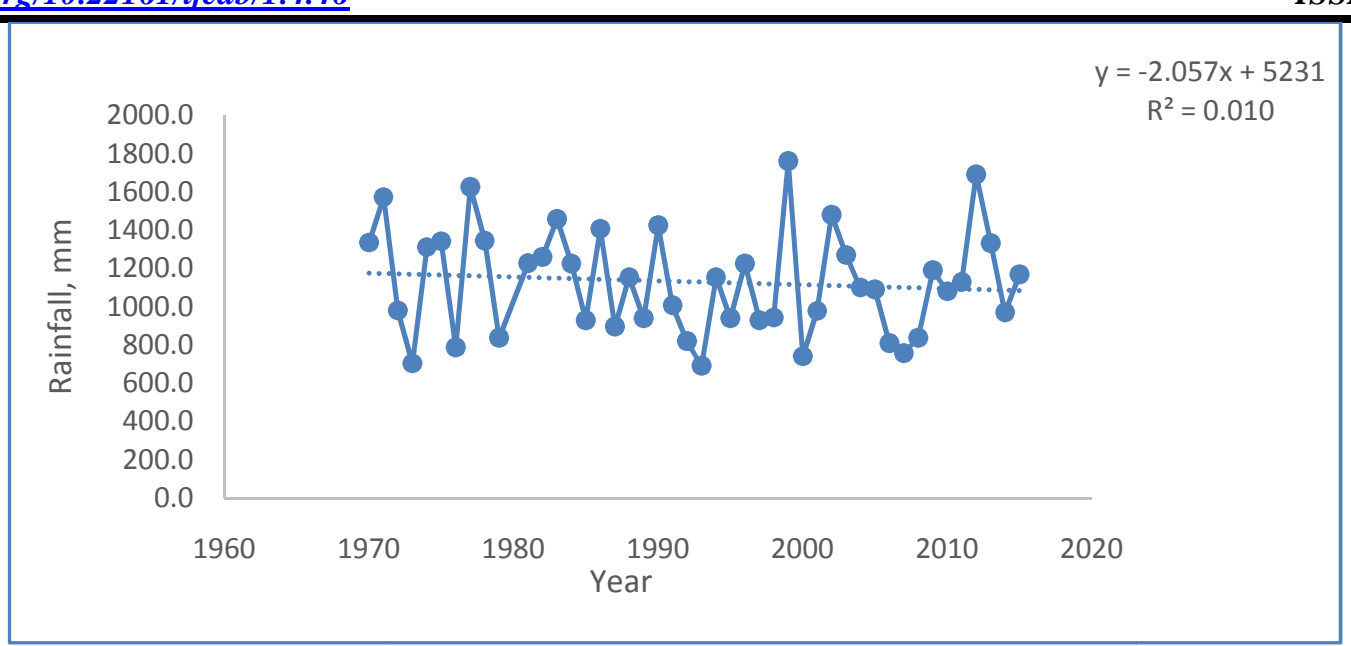

Fig.1: Annual rainfall variation of the study area (Duration 1971-2015)

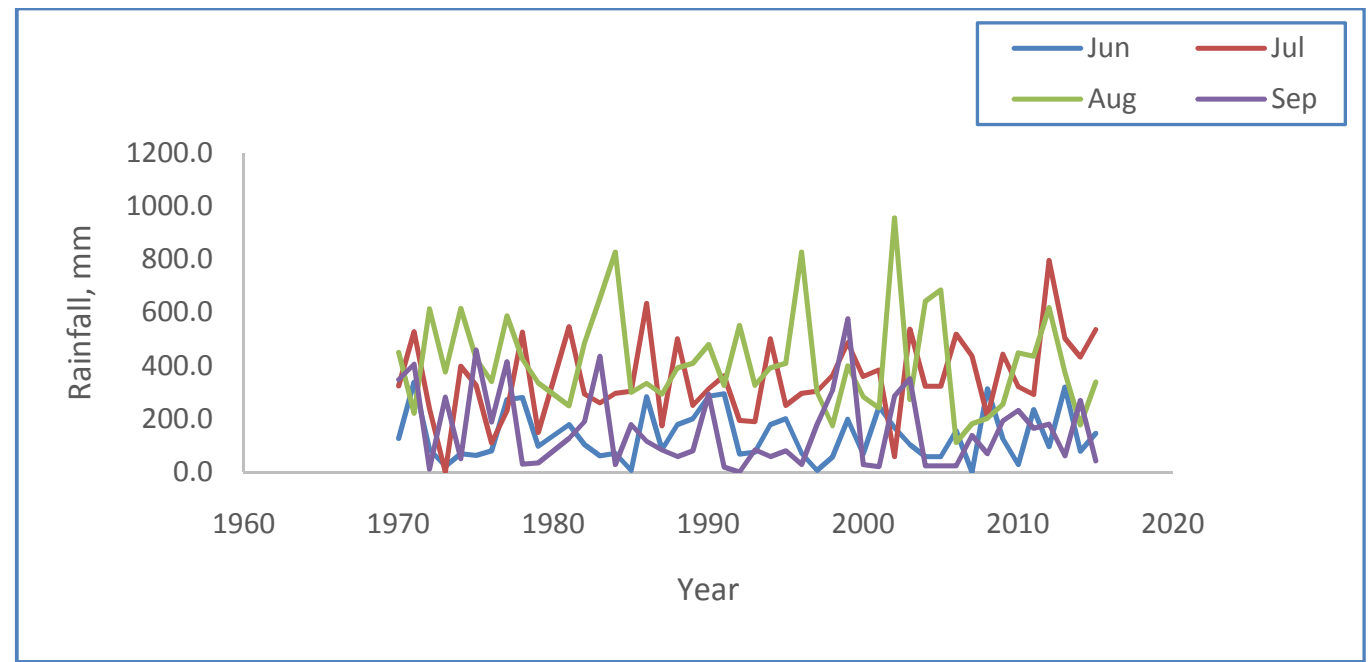

Fig.2: Seasonal rainfall variation of the study area (Duration 1971-2015)

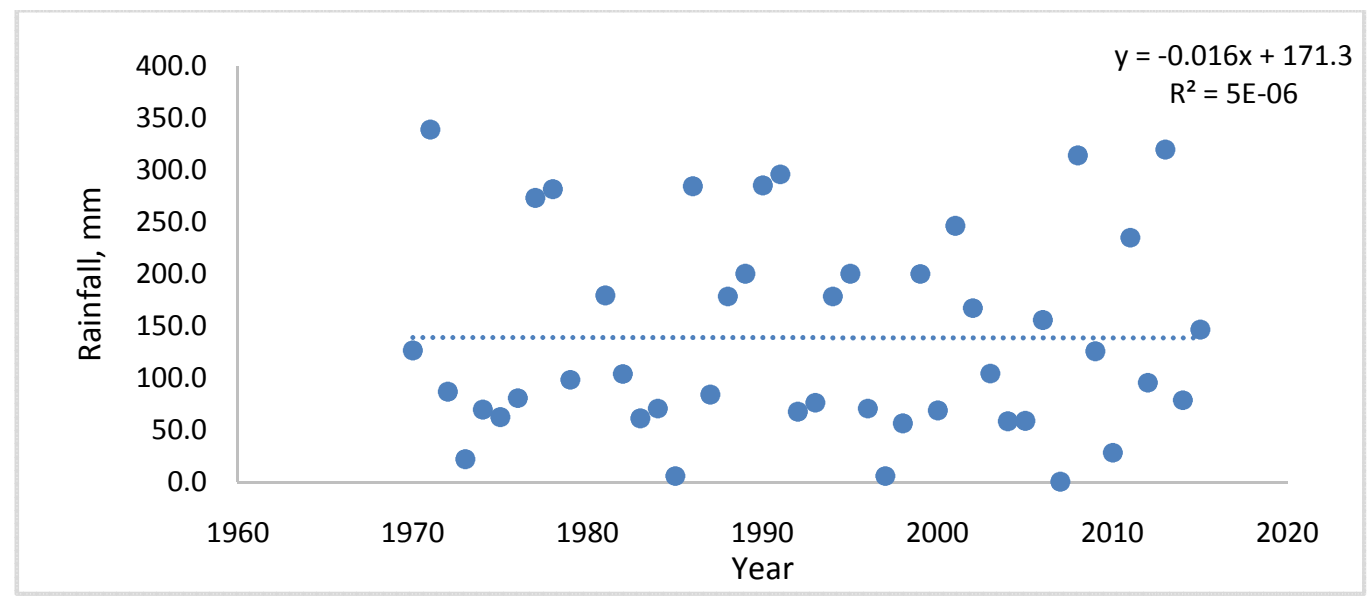

Fig.3: Regression Analysis of yearly June month variation 


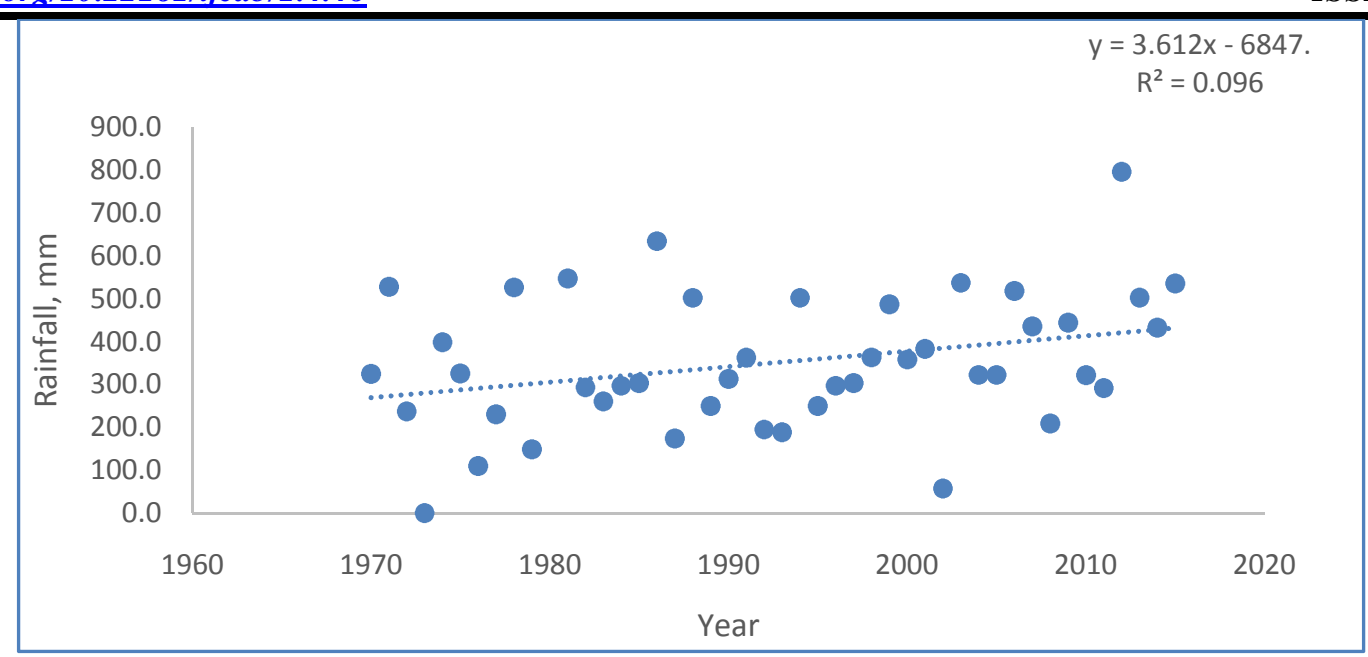

Fig.4: Regression Analysis of yearly July month variation

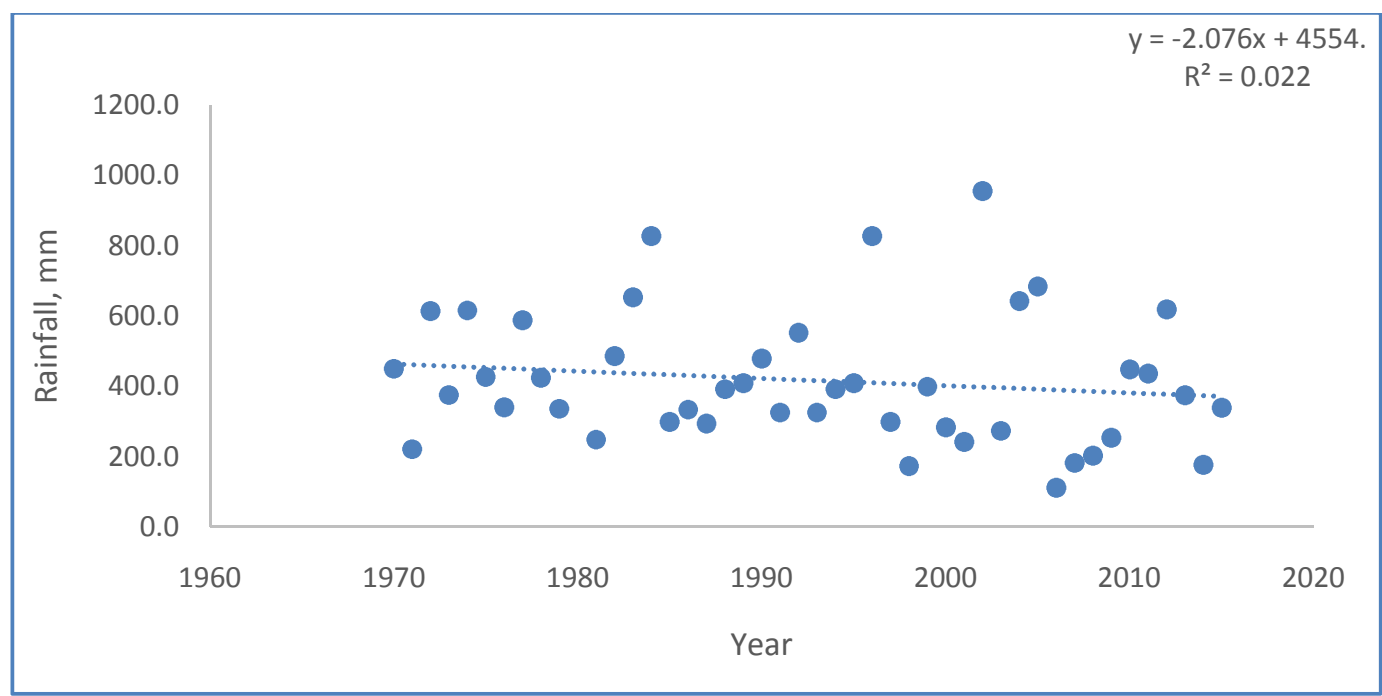

Fig.5: Regression Analysis of yearly August month variation

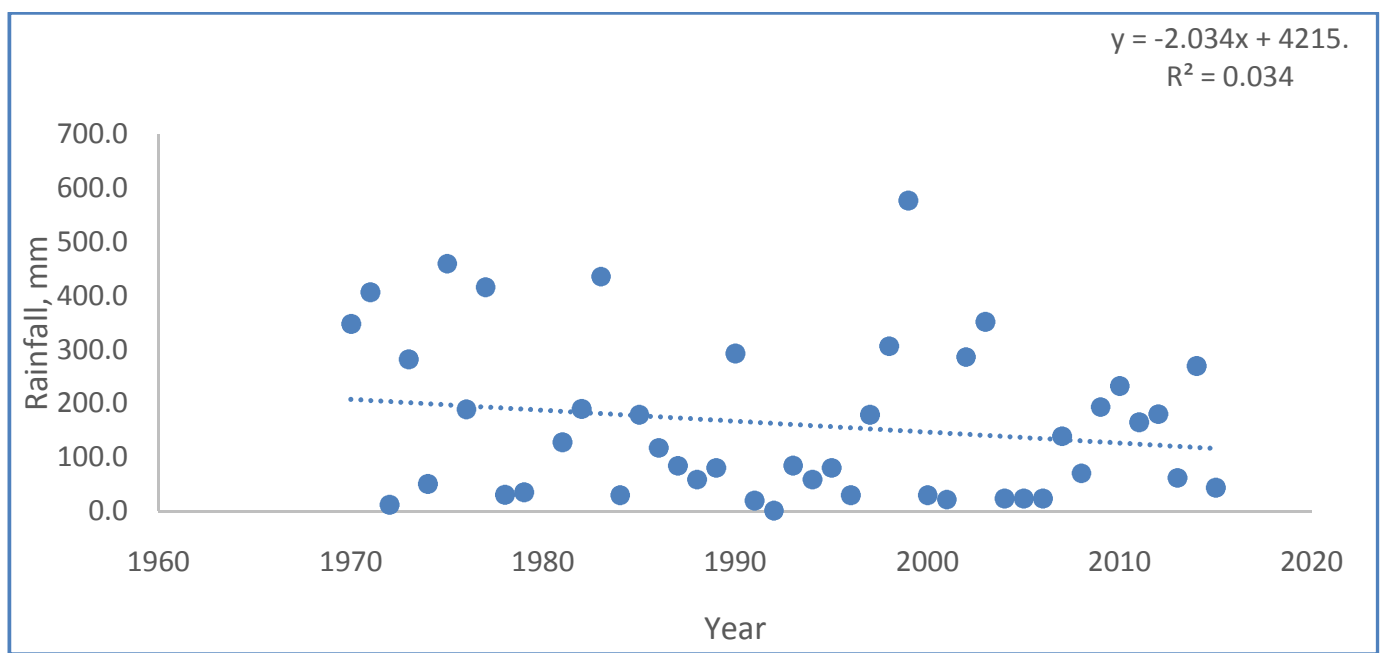

Fig.6: Regression Analysis of yearly September month variation

\section{CONCLUSION}

This study was performed to identify the annual as well as seasonal variation of rainfall as well as Rainfall Trend. The Mann-Kendall, Sen's Slop Estimator and Regression analysis was performed on annual time series data along with seasonal time series data of fourmonths June, July, August and September respectively. The value of Mann-Kendall test showed negative trend for June, August and September 
rainfall data, However July month shown an increasing trend. The Sen's Slope estimator and regression analysis values which has been calculated also shown the similar kind of trend. It can be concluded from the study that theannual rainfall observations obtained over time are independent, identically distributed and there are variability shown in annual rainfall pattern. Mann-Kindle test result suggested that there are no significant trend in annual rainfall pattern over long term. However regression trend line of annual rainfall has shown a bit of downtrend over the years. Also it can be concluded that some sessional rainfall trend changes happened over the years as three months (June, Aug, September) shown some downtrend however the trend of rainfall in July was found increasing for the study area over a considerable time period of 44 years.

\section{REFRENCES}

[1] Chhabra, B. M., Prakasa Rao, G. S. and Joshi U. R., (1997). A comparative study of differences in the averages of temperatures and rainfall over the Indian stations during the periods 1931 - 60 and 1961-90. Mausam 48: 1, 65-70.

[2] Easterling D R, Evans J L Groisman P Y, Karl T R, Kumbel K E, Ambenje P. (2000).Observed variability and trends in extreme climate events: a brief review.Bulletin of the American Meteorological Society $81: 417-425$.

[3] Francis, P.A. and Gadgil, S., (2006). Intense rainfall events over the west coast ofIndia. Meteorol Atmos. Phys., doi 10.1007/s00703-005-0167-2.

[4] Griffiths G M, Salinger M J, Leleu I. (2003). Trends in extreme daily rainfall across the south Pacific and relationship to the South Pacific convergence zone. International Journal of Climatology 23: 847 - 869.

[5] Guhathakurta, P and Rajeevan, M. (2006). Trends in Rainfall Patterns over India. National Climate CentreResearch Report, India Meteorological Department, Pune, India.

[6] Guhathakurta. P., and Rajeevan. M., (2006), Trends in the rainfall pattern over India, NCC Research Report No 2/2006, May 2006, India Meteorological Department, pp 23.

[7] Haylock M. R. et al., (2006). Trends in total and extreme south American rainfall in 1960-2000 and links with sea surface temperature. Journal of Climate 19:1490-1512.

[8] Haylock M. R., Nicholls N, (2000). Trends in extreme rainfall indices for an updatedhigh quality data set for Australia 1910 - 1998. International Journal ofClimatology 20: 1533 - 1541.

[9] Jain, S.K. and Kumar,V. (2012). Trend analysis of rainfall and temperature data for India. Current
Science, 102(1):37-49.

[10] Kendall, M.G., (1975). Rank Correlation Measures, Charles Griffin, London.

[11] Kunkel K E. (2003). North American trends in extreme precipitation. Natural Hazards29: $291-305$.

[12] Mann, H.B.,(1945). Non-parametric tests against Trend, Econometrica 13. 245-259.

[13] Shouraseni Sen Roy and Balling Jr R C. 2004; Trends in extreme daily precipitationon indices in India. Int. J. Climatol., 24: 457 - 466.

[14] Sen, P.K. (1968). Estimates of the Regression coefficient based on Kendall's tau. Journal of the American Statistical Association, 63: 1379-1389. 